\title{
Article
}

\section{Fatigue Life and Reliability of Steel Castings through Integrated Simulations and Experiments}

\author{
Muhammad Azhar Ali Khan ${ }^{1, *}$, Anwar Khalil Sheikh ${ }^{2}$, Zuhair Mattoug Gasem ${ }^{2}$ and Muhammad Asad ${ }^{1}$ (D) \\ 1 Mechanical Engineering Department, College of Engineering, Prince Mohammad Bin Fahd University, \\ Alkhobar 34754, Saudi Arabia; masad@pmu.edu.sa \\ 2 Mechanical Engineering Department, King Fahd University of Petroleum and Minerals, \\ Dhahran 31261, Saudi Arabia; anwarks1948@gmail.com (A.K.S.); zuhair@kfupm.edu.sa (Z.M.G.) \\ * Correspondence: mkhan6@pmu.edu.sa
}

Citation: Khan, M.A.A.; Sheikh, A.K.; Gasem, Z.M.; Asad, M. Fatigue Life and Reliability of Steel Castings through Integrated Simulations and Experiments. Metals 2022, 12, 339. https://doi.org/10.3390/ met12020339

Academic Editors: Ricardo Branco, Filippo Berto and Shengchuan Wu

Received: 29 December 2021

Accepted: 25 January 2022

Published: 15 February 2022

Publisher's Note: MDPI stays neutral with regard to jurisdictional claims in published maps and institutional affiliations.

Copyright: (c) 2022 by the authors. Licensee MDPI, Basel, Switzerland. This article is an open access article distributed under the terms and conditions of the Creative Commons Attribution (CC BY) license (https:// creativecommons.org/licenses/by/ $4.0 /)$.

\begin{abstract}
The quality and performance of steel castings is always a concern due to porosities formed during solidification of the melt. Nowadays, computational tools are playing a pivotal role in analyzing such defects, followed by their minimization through mold design optimization. Even if the castings are produced with defects in a permissible range, it is important to examine their service life and performance with those defects in a virtual domain using simulation software. This paper aims to develop a methodology with a similar idea of simulation-based optimization of mold design and predictions of life and reliability of components manufactured with minimized casting defects, especially porosities. The cast parts are standard fatigue specimens which are produced through an optimized multi-cavity mold. X-ray imaging is done to determine the soundness of cast parts. Experimental work includes load-controlled fatigue testing under fully reversed condition. The fatigue life of specimens is also simulated and compared with the experimental results. The classical strength-stress model is used to determine the reliability of cast parts through which a safe-load induced stress of steel castings is determined. Finally, probability distributions are fit to the reliability results to develop the reliability models. It is found that porosities can be minimized significantly in the mold design phase using casting simulations. Nevertheless, some porosities are bound to exist, which must be included in realistic estimation of fatigue life and reliability of cast parts.
\end{abstract}

Keywords: metal casting; mold design; simulation; optimization; fatigue life; reliability

\section{Introduction}

Steel casting is widely used for components with high requirements regarding strength, toughness, and wear resistance [1]. Due to a large variety of grades available for steel, it is convenient to adjust the properties such as strength and hardness, corrosion and wear resistance, and operating temperatures. The key advantage of casting steel is obtaining a near net shape product with almost any level of intricacy. However, steel tends to form pores during solidification, which must be considered during the mold design. It is essential to include suitable gate geometries and feeders to minimize shrinkage porosities, as well as a proper venting system for resulting gases, to minimize gas porosities. These porosities often pose challenges in quality, life and reliability of steel castings while in service. Hence, these porosities must be included in realistic fatigue life and reliability estimates of steel castings.

The advancements in computational tools have led to the visualization of both the casting process and performance in a completely virtual domain. In pursuit of a robust mold design, it allows a shift from the conventional trial-and-error approach to a modern proof-of-concept approach which makes the process faster, more efficient and less expensive [2]. The simulation-based optimization is a relatively new idea for developing a robust mold design [3-7]. Demler et al. used casting simulation software to determine 
suitable casting parameters and to predict porosity in components of a drive train made of low alloy steel [4]. Simulation results suggested a suitable casting temperature of $1680{ }^{\circ} \mathrm{C}$ together with a casting time of $10 \mathrm{~s}$. The exact locations of feeders are also identified using simulations to ensure proper filling of the molten metal in critical areas of the casting cavity. Lei et al. studied the optimization of the casting system of turbocharger castings using MAGMASoft [5]. The castings originally produced in the foundry are found with defects such as air entrapment, shrinkage and micro-shrinkage, etc. The causes of such defects are first identified using casting simulations, followed by mold design and process parameter optimization. In this regard, the geometry of the sprue and sprue base is significantly modified, and the pouring time is reduced. This resulted in a steadier flow of the melt within the mold together with a faster filling time. It is reported that the defected casting rate dropped from $20 \%$ to $10 \%$ using simulation-based modified casting system. Sunanda et al. studied the sand casting optimization of a medium carbon steel pulley using Procast software [6]. The main problem is a very heated central region of the pulley casting during solidification leading to hotspots and shrinkage porosity. The issue is addressed by modifying dimensions of sprue, risers and even the ingates in the casting system. Kumar et al. optimized the gating system of a rotary adapter produced by an investment casting process [7]. The casting process is simulated using Procast. Various parameters are considered such as air, flow length, foreign metal entrapment, in gate velocity and gating ratio. The results for each simulation run are examined in terms of in gate entry velocity, fraction solid, shrinkage porosity, etc. Finally, an optimized gating system is developed, simulated and found free from the defects.

A holistic approach is to include the defects, particularly porosities, predicted in casting simulations while determining the service life and reliability. Efforts have been made in the past towards such integration [8-11]. Sheikh et al. studied the effect of mold design optimization on fatigue life and reliability of cast parts [8]. Casting simulations are used to minimize porosity in cast parts followed by their life prediction and reliability assessment through finite element simulations. A comparison of simulation and experimental results validated the developed methodology and its application to any cast metal/alloy. Schmiedel et al. investigated the fatigue life of cast $42 \mathrm{CrMo} 4$ steel in the range from high to very high cycle fatigue [9]. The most detrimental defect in cast state is found to be microshrinkage. A short crack growth model based on considerations of Miller is adapted to examine the fatigue life by using the experimental fatigue data and fracture morphology.

This paper presents an integrated approach of utilizing simulations and experiments to estimate fatigue life and reliability of steel castings. Unlike the conventional method of drawing specimens from already cast plates, rods, blocks or even actual castings, the fatigue specimens are considered to be simple cast parts. A multi-cavity initial mold design is developed, simulated and optimized to produce specimens with minimum porosity. The specimens are cast using an optimized mold design for mechanical testing. Next, fatigue life of specimens is simulated using ABAQUS and the results are compared with experimental results to validate the model. Reliability computations are done using a StressStrength model which considers both strength and stress as variables. Finally, probability distributions are fit to the reliability results to develop the reliability models. A graphical representation of the methodology used in this study is presented in Figure 1. 


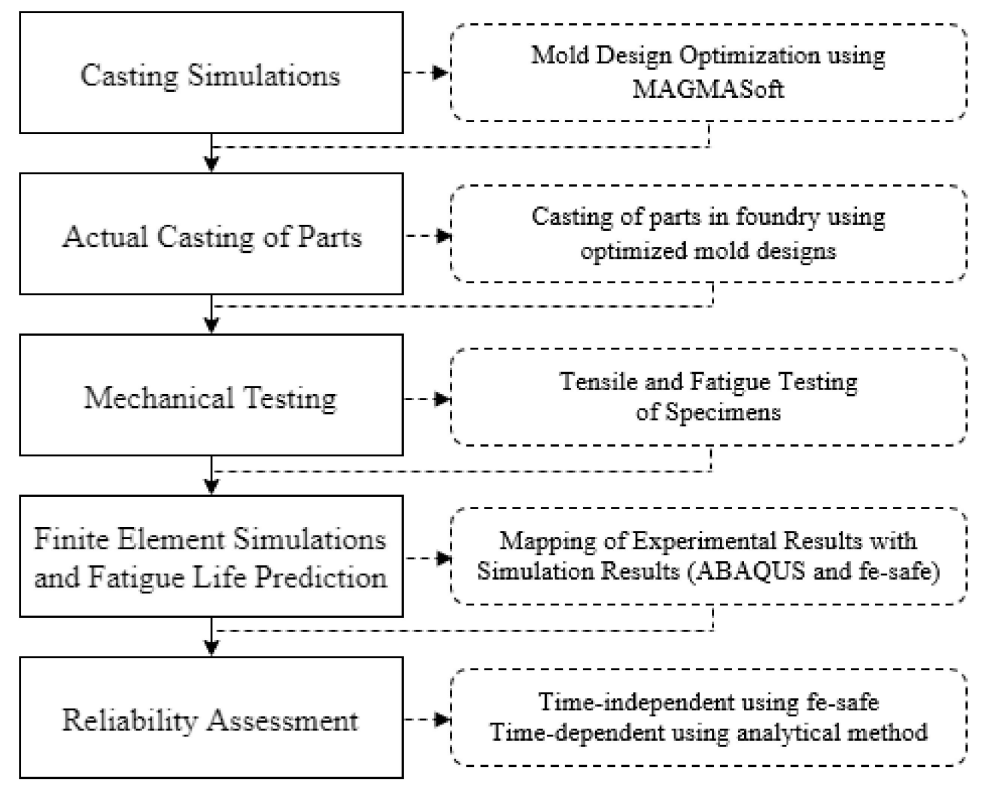

Figure 1. Methodology to estimate fatigue life and reliability of steel cast specimens.

\section{Materials}

The selected material for this work is ASTM A216 WCB steel due to its widespread use in casting industry. It offers a good mix of strength and ductility, making it suitable to be employed in casting of engineering components. The chemical composition and mechanical properties at room temperature for this steel alloy are provided in Table 1 . In addition to the cast material, the selected mold material for this work is Furan sand, which is a chemically bonded sand and does not require baking of the mold. Furan sand molds are compact and provide numerous advantages such as accuracy in casting size, clear outline of casting, smooth surface, good appearance quality, and compact microstructure. Table 2 lists the important properties of the mold material.

Table 1. ASTM A216 WCB steel material specification.

\begin{tabular}{cccccccccc}
\hline \multicolumn{10}{c}{ Chemical Composition (Wt.\%) } \\
\hline Fe & $\mathrm{C}$ & $\mathrm{Mn}$ & $\mathrm{Si}$ & $\mathrm{P}$ & $\mathrm{S}$ & $\mathrm{Ni}$ & $\mathrm{Cr}$ & $\mathrm{Mo}$ & $\mathrm{Cu}$ \\
\hline 96.2 & 0.3 & 1 & 0.6 & 0.035 & 0.35 & 0.5 & 0.5 & 0.2 & 0.3 \\
\hline \multicolumn{8}{c}{ Mechanical Properties (at room temperature as per ASTM A216) } \\
\hline \multicolumn{7}{c}{ Tensile Strength (MPa) } \\
\hline \multicolumn{7}{c}{485} & \multicolumn{3}{c}{ Elongation (\%) } \\
\hline
\end{tabular}

Table 2. Mold Material Specification.

\begin{tabular}{|c|c|}
\hline Mold Material & Furan \\
\hline Base Materials & Silica Sand \\
\hline Binder & Furan \\
\hline Water Content & $0 \%$ \\
\hline Initial Temperature & $20{ }^{\circ} \mathrm{C}$ \\
\hline \multicolumn{2}{|c|}{ Erosion Properties } \\
\hline Reference Velocity & $3 \mathrm{~m} / \mathrm{s}$ \\
\hline Reference Time & $6 s$ \\
\hline \multicolumn{2}{|c|}{ Sand Inclusion Parameters } \\
\hline Sand grain diameter & $240 \mu \mathrm{m}$ \\
\hline Sand grain density & $2650 \mathrm{~kg} / \mathrm{m}^{3}$ \\
\hline
\end{tabular}




\section{MAGMASoft Simulations for Casting Specimens}

A usual practice in mechanical characterization of metal castings is extracting the specimens from plates, blocks, rods or even actual cast parts. This approach is reasonable when the properties and behavior of actual castings need to be determined under static and dynamic loading. The process-oriented nature of this work demands considering fatigue specimens shown in Figure 2 as a simple cast part. Therefore, a mold is initially designed and simulated to understand filling and solidification behavior and defect predictions, followed by its optimization to minimize porosities.
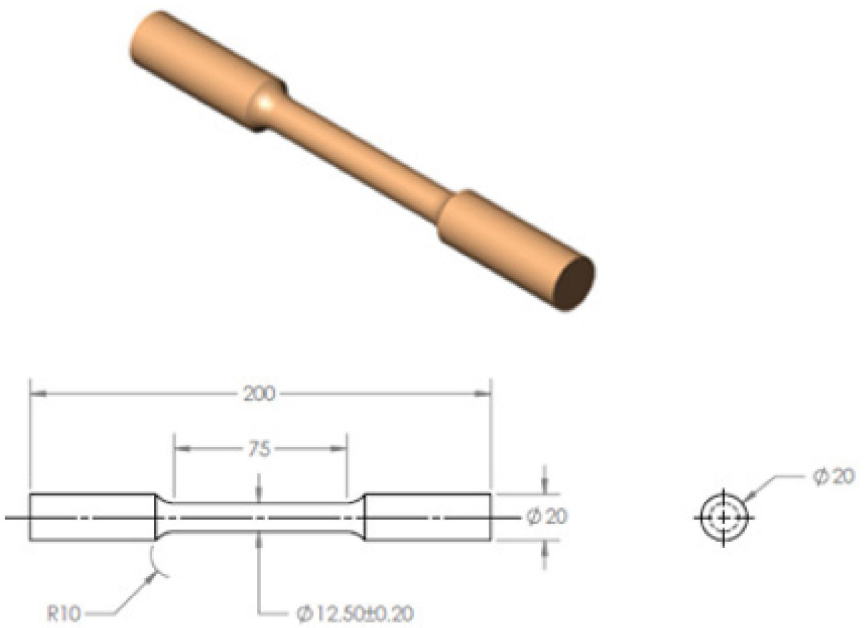

Figure 2. Fatigue specimen geometry (All dimensions are in $\mathrm{mm}$ ).

Casting simulations are set up in MAGMASoft using different perspectives within the software. To begin with, casting layout, i.e., assembly of components, such as pouring basin, sprue, runner, gates, casting, risers, etc., is either drawn or imported from a CAD software in the Geometry perspective. A mold is also created in the same perspective. Next, the casting layout and mold is discretized using Mesh perspective. Following mesh generation, material (cast alloy and mold) properties and process parameters are defined using the Definition perspective. If needed, Optimization perspective can be used to set criteria for autonomous optimization of casting layout. The required results are defined, and simulation settings are done using the Simulation perspective. At the end of the simulation, the results are viewed in the Results perspective. A flow chart of the simulation sequence in MAGMASoft is presented in Figure 3.

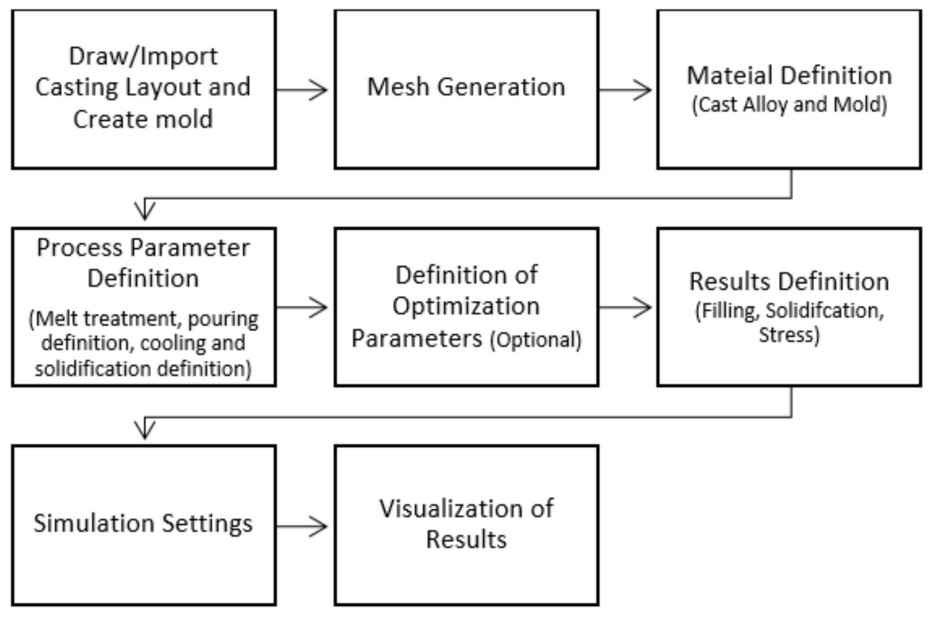

Figure 3. Simulation sequence in MAGMASoft. 
The optimized mold designs for casting fatigue specimens are developed as follows:

(a) Initial Mold Design: This mold design requires theoretical calculations, casting standards, design expertise of foundrymen and daily foundry practices.

(b) Casting Simulation of Initial Mold Design: The resulting mold from (a) is simulated for filling and solidification behavior, stress distribution and porosity prediction in specimens using MAGMASoft.

(c) Optimized Mold Design: Based on the results obtained in (b), the mold design is carefully optimized for casting layout and/or process parameters. It is important to set the objectives of this optimization, for example, yield maximization, defect minimization, residual stress minimization, etc. In this study, the main objective is set as porosity minimization.

The details of mold design optimization are presented in the following sub-sections.

\subsection{Initial Mold Design}

The initial mold design is modeled in SOLIDWORKS as shown in Figure 4. It is a multi-cavity mold with sprue-runner configuration, where, instead of choking each casting separately, a single choke is used in the runner area. Casting simulations are done using MAGMASoft. The casting layout is divided into 1,975,320 volume elements using a cubical mesh. MAGMASoft offers a full range of material properties and heat transfer settings as an input to simulations [12]. The pouring temperature is set to be $1630^{\circ} \mathrm{C}$ whereas the mold is assumed to be at room temperature, i.e., $20^{\circ} \mathrm{C}$. Pouring time is defined as $15 \mathrm{~s}$. With these simulation settings, the feeding effectivity calculated by the software is $\sim 30 \%$. From a results perspective, it is decided to run simulations for filling and solidification sequence, residual stress distribution, and magnitude and locations of porosities.

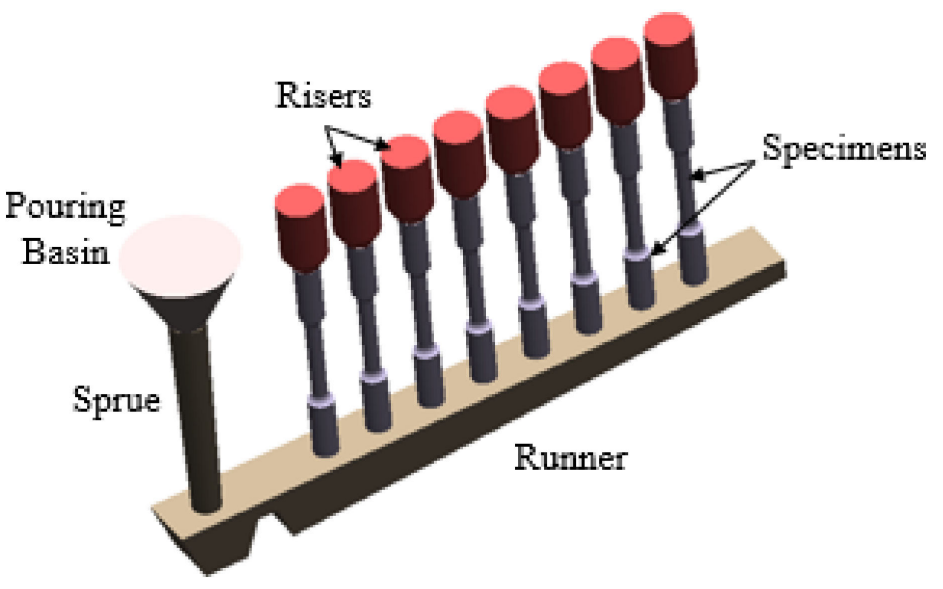

Figure 4. Initial mold design for casting fatigue specimens.

Figure 5a depicts the temperature profile of the mold after pouring. As expected, solidification continues with a drop in temperature of the melt. It can be observed that solidification began with the test section of the specimens and all specimens are solidified at $50 \%$ solidification as shown in Figure $5 \mathrm{~b}$. The solidification time is recorded to be $8 \mathrm{~min}$ with risers being the last region to solidify in the mold. The distribution of residual stresses is presented in Figure $5 \mathrm{c}$ where stresses are concentrated in the test section of the specimens. The maximum residual stress at ejection is about $50 \mathrm{MPa}$, which is a typical magnitude of residual stress in steel castings [13]. 


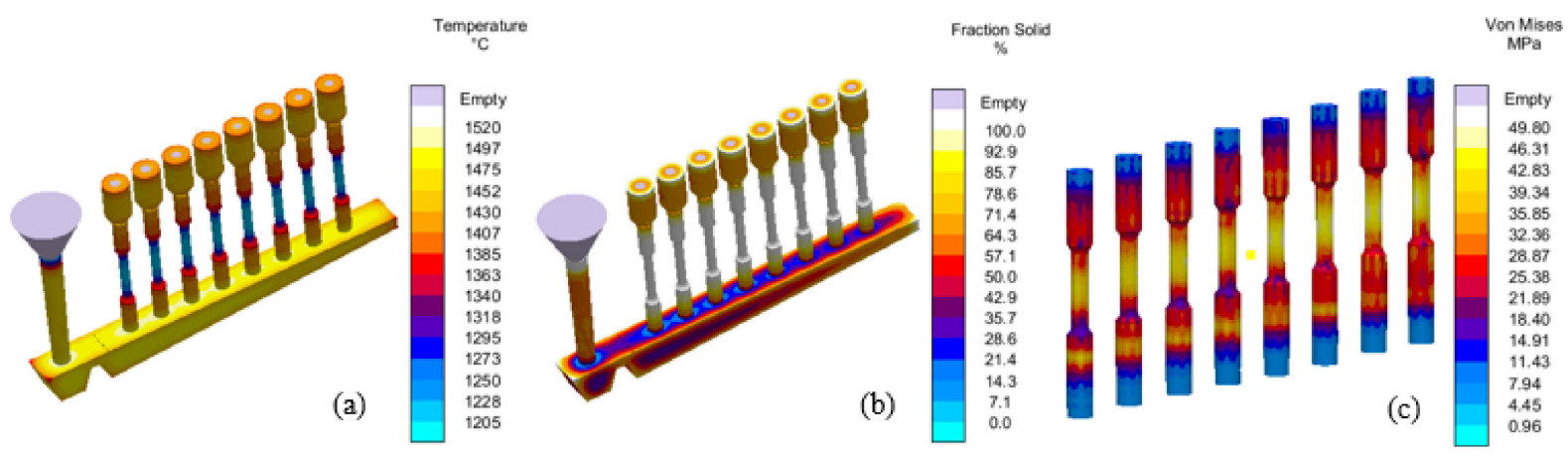

Figure 5. (a) Temperature profile within the mold at 50\% solidification, (b) Percentage fraction solid at $50 \%$ solidification, and (c) Residual stresses distribution.

In terms of porosity, the $\mathrm{X}$-ray view shown in Figure 6a revealed only one specimen to be pore-free. However, significant porosity is observed in specimens 4, 6, 7 and 8 as shown in Figure 6. Despite the porosity being observed in the grips of test specimens, it had to be minimized for the reason that these specimens are simple cast products. Microporosity is distributed throughout the casting layout with a maximum microporosity to be $\sim 4 \%$ as shown in Figure 6b. Figure $6 \mathrm{c}$ shows the total porosity in the specimens which is found to be nearly the same in all specimens and could be minimized with a better mold design.

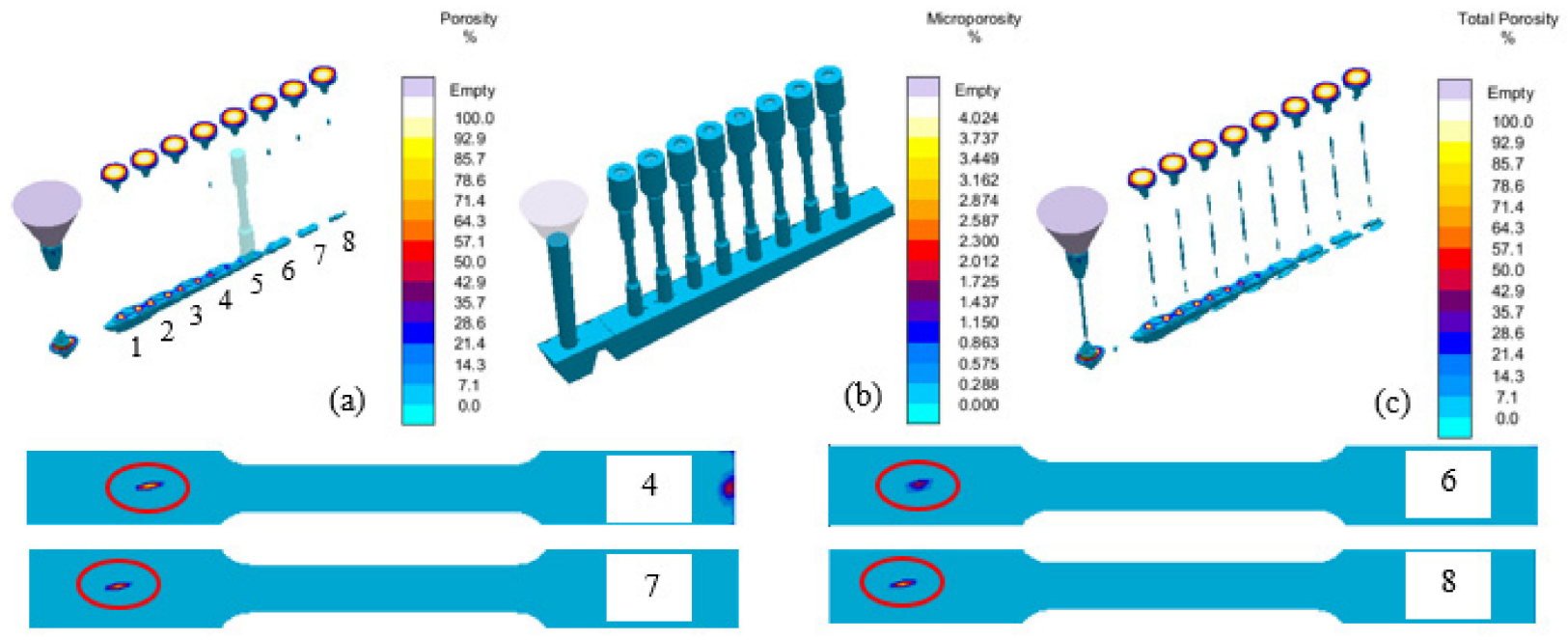

Figure 6. X-ray views of (a) porosity, (b) microporosity and (c) total porosity in simulated cast specimens using initial mold design.

\subsection{Optimized Mold Design}

The optimization problem is to obtain high quality casting nearly free from defects especially porosity. The objective function is to minimize porosity in castings (test specimens in this case) so that they have a mechanical performance similar to their sound counterparts. The design variables are elements of gating and runner system (Shape and size of sprue, choking, runner geometry and shape, addition of exothermic sleeves, etc.) and the constraints are cast and mold material, melting and pouring temperatures. The new mold design includes changes such as removal of choke from the sprue, choke at the beginning of runner bar, and use of exothermic sleeves. The new casting layout, as shown in Figure 7 is divided into 1,989,414 elements. The simulation settings are kept the same as already discussed earlier. Once again, simulation results indicated temperature gradient in specimens as shown in Figure 8a, and the risers are found to solidify at the end as shown in Figure 8b. It took 16 min for complete solidification using this mold design. 
Residual stresses in specimens are shown in Figure $8 \mathrm{c}$ which are reduced from $\sim 50 \mathrm{MPa}$ to $30 \mathrm{MPa}$. Once again, the X-ray view of the software, as shown in Figure 9, enabled analysis of the simulated porosity, microporosity, and total porosity in specimens. It can be observed that nearly the same porosity is predicted in all specimens as shown in Figure 9a. The connections between runner and specimens are found to be pore-free in the new mold design. Some microporosity is observed, which is uniformly distributed in the specimens as shown in Figure $9 \mathrm{~b}$. Total porosity is found to be identical and reduced in all specimens as compared to the total porosity shown in Figure 6c.

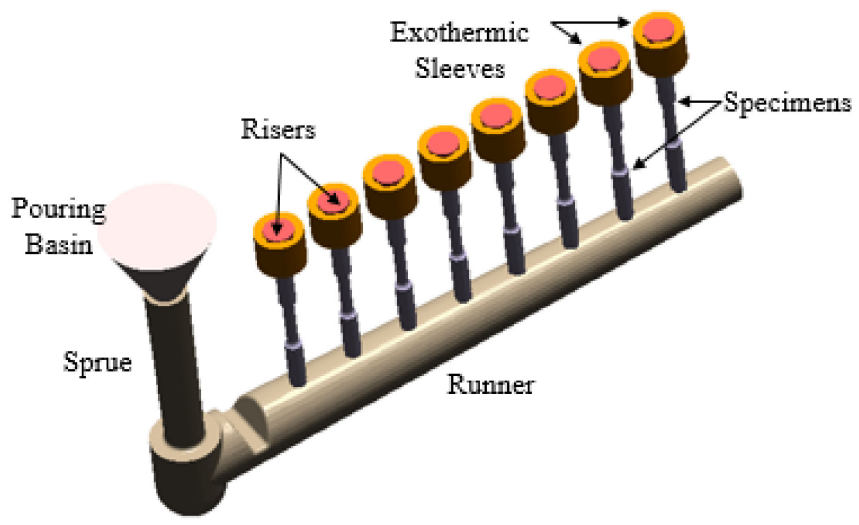

Figure 7. Optimized mold design for casting fatigue specimens.

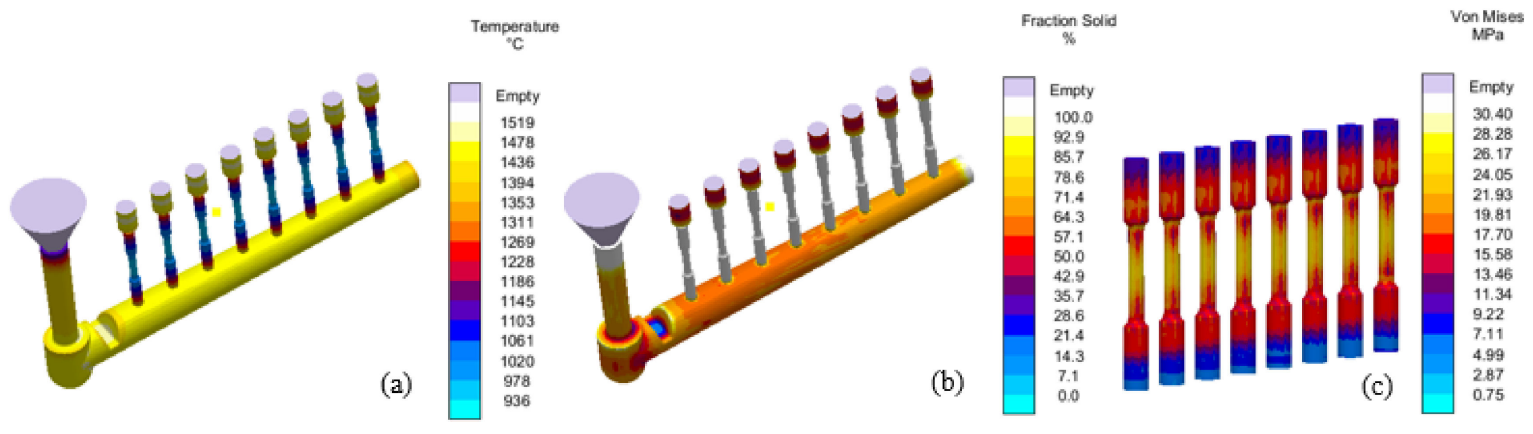

Figure 8. (a) Temperature profile within the mold at 50\% solidification, (b) Percentage fraction solid at $50 \%$ solidification, and (c) Residual stresses in specimens at ejection.

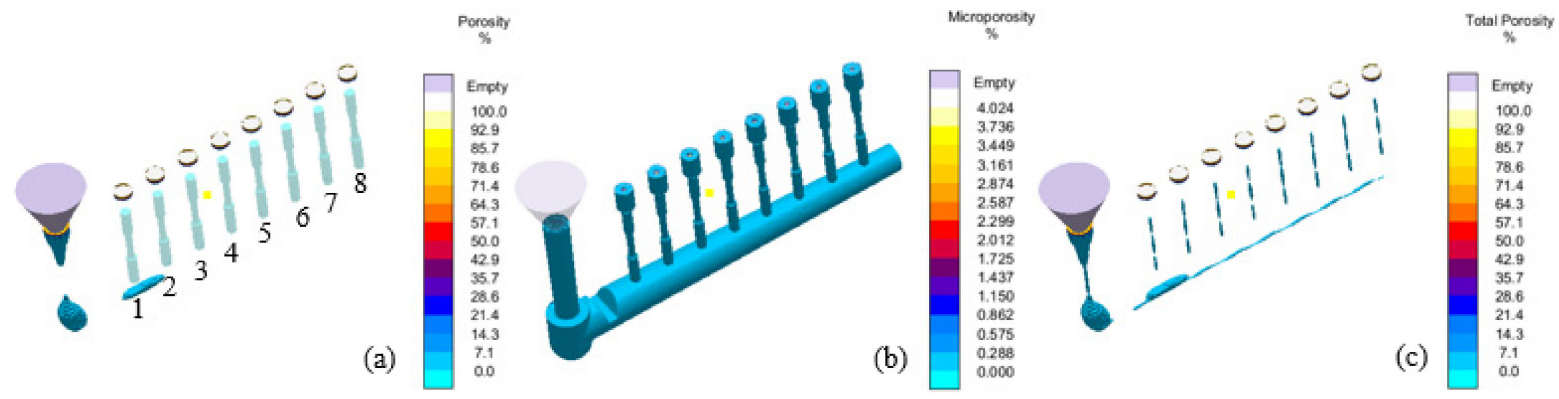

Figure 9. X-ray views of (a) porosity, (b) microporosity and (c) total porosity in simulated cast specimens using optimized mold design.

\section{Casting and Mechanical Testing}

The preparation of a mold requires a pattern which is an exact replica of the part to be cast. A wooden pattern of the optimized casting layout is developed as shown in Figure 10a to compact sand around it thereby forming a mold. The resulting sand mold 
is shown in Figure 10b. In order to avoid direct interaction of molten metal with the mold material, a dense layer of zirconium-based coating is applied to the mold surface. Mold properties evaluation revealed a compression strength of $18 \mathrm{~kg} / \mathrm{cm}^{2}$ and a scratch hardness of $28-29$. The pouring temperature is set to $1590-1600{ }^{\circ} \mathrm{C}$ for which steel is melted in an induction furnace which offers ease of operation, high quality of products, better metallurgical functions, and lower oxidation losses. The steel is deoxidized using Aluminum in the ladle prior to pouring into the mold. It is ensured to perform casting at similar conditions which are used in the simulations. Figure 10c shows the entire casting just after the removal of mold. As mentioned earlier, the specimens are considered as simple cast parts which are obtained after removing pouring basin, sprue, runner bar, and risers. The specimens are then annealed at $920^{\circ} \mathrm{C}$, held for half an hour, and cooled in furnace. Specimens after heat treatment are machined to final dimensions as per the ASTM E-466 standard [14]. The quality and surface finish of the specimens is enhanced during machining.

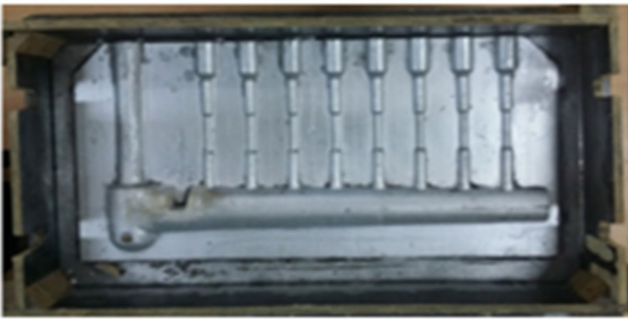

(a)

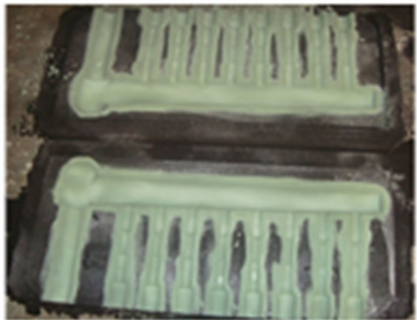

(b)

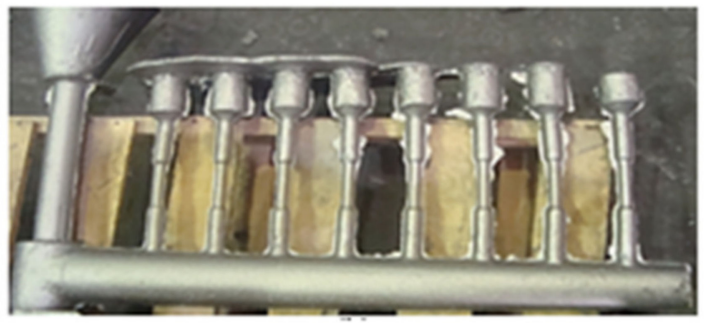

(c)

Figure 10. (a) Pattern, (b) Sand mold and (c) Cast Specimens prior to cleaning and finishing.

The quality of cast specimens is evaluated using radiographic examination. The results of X-ray imaging are presented in Figure 11. Some porosity is revealed within the test section of specimens which is observed as difference in appearance of grips and the test section as shown in Figure 11. However, the distribution of porosity from one specimen to another is not much different.
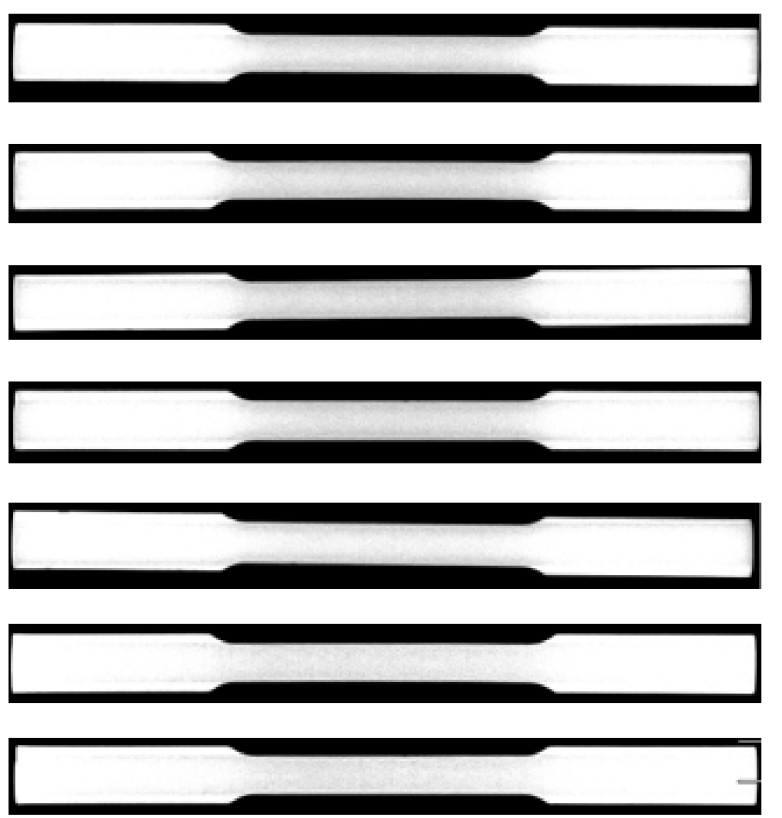

Figure 11. X-ray imaging of steel fatigue specimens.

The fatigue testing is done as per the ASTM E-466 standard [14]. The experimental setup is presented in Figure 12. Fully revered conditions where $R=-1$ is used to test all 
specimens under cyclic loading. The frequency of testing is set to be $5 \mathrm{~Hz}$ for all specimens. Fatigue testing is done until fracture for all specimens except for runout condition which is $10^{6}$ cycles in this study. A careful selection of stress amplitude has led to the testing of six specimens for finite life and one for the infinite life. Table 3 lists the stress amplitude selected and number of cycles to failure for each specimen. Figure 13 depicts the SN curve developed as a results of fatigue testing of steel specimens.
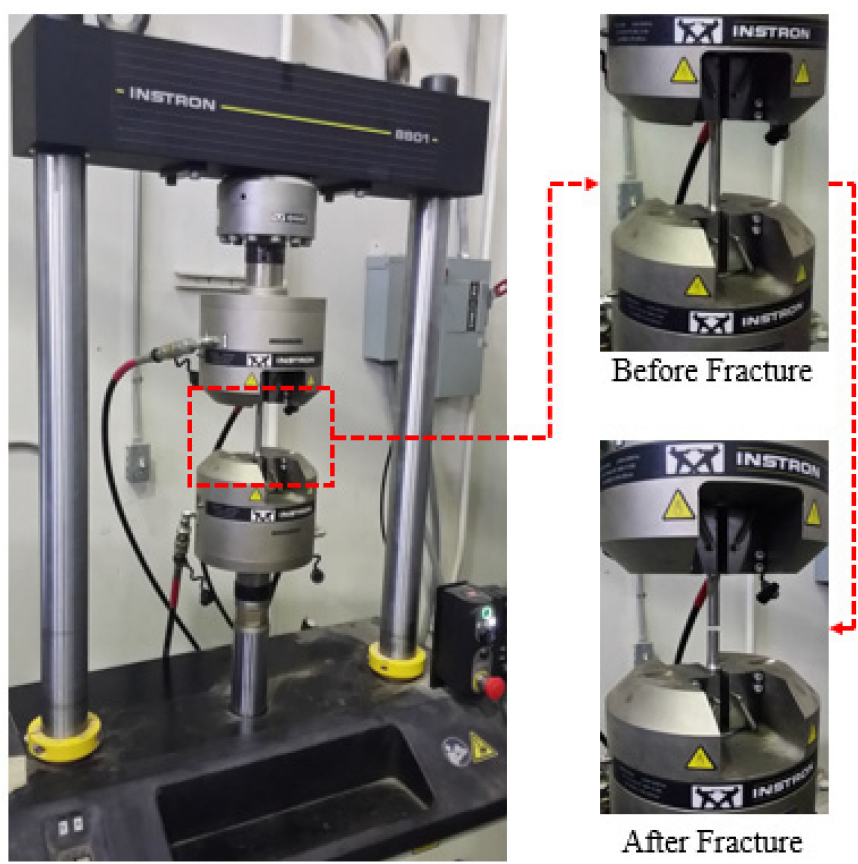

Figure 12. Experimental setup for fatigue testing.

Table 3. Experimental results for fatigue testing of specimens.

\begin{tabular}{cccc}
\hline Specimen ID & Stress Applied for Test (MPa) & Frequency $\mathbf{( H z )}$ & Fatigue Life (Cycles) \\
\hline $\mathrm{S}^{\prime}$ & 326 & 5 & 62 \\
$\mathrm{~S}^{\prime}$ & 244 & 5 & 6545 \\
$\mathrm{~S}^{\prime}$ & 204 & 5 & 20,561 \\
$\mathrm{S4}^{\prime}$ & 163 & 5 & 56,893 \\
$\mathrm{S5}^{\prime}$ & 122 & 5 & 145,089 \\
$\mathrm{S6}^{\prime}$ & 81 & 5 & 535,564 \\
$\mathrm{~S}^{\prime}$ & 41 & 5 & $3,061,195$ \\
\hline
\end{tabular}

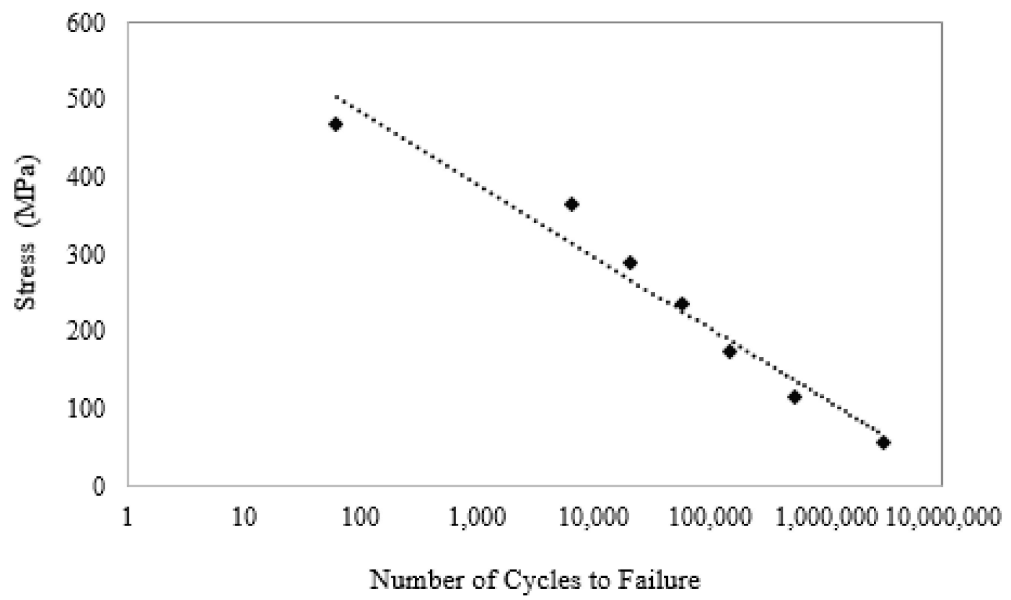

Figure 13. S-N curve for cast steel specimens. 


\section{Fatigue Simulations and Life Prediction}

\subsection{Simulation Procedure}

Fatigue testing is simulated by doing (a) finite element elastic stress using the load in experimental fatigue testing and (b) fatigue life prediction using multi-axial strain-life approach using stress fields predicted in (a). The results of porosity from MAGMASoft are mapped to Finite Element Analysis (FEA) nodes using MAGMAlink. MAGMAlink allows user to import and export results to and from other softwares into and out of MAGMASoft. The translation and rotation features enable FEA mesh to accurately overlay the MAGMASoft model. FEA mesh is developed in ABAQUS prior to stress simulation. MAGMAlink provides the magnitude of nodal porosity which has to be integrated in ABAQUS. The node sets and nodal porosity data are included in the ABAQUS input file which contains all commands, boundary conditions, and properties required to run the stress simulation. A comparison of experimental and simulation results ensures competency of the model in predicting the fatigue life prediction.

The element type used for fatigue simulations is an eight-node linear brick element (C3D8R). The boundary conditions are set to replicate the actual testing conditions. The specimen is held fixed from one end and a uniformly distributed load, reflecting the actual loading condition for each specimen, is applied to the other end as shown in Figure 14a. Mesh sensitivity analysis confirmed a $1 \mathrm{~mm}$ node spacing suitable for all simulations. The resulting mesh is shown in Figure $14 \mathrm{~b}$. The finite element model developed with these specifications consist of 83,433 elements, 90,373 nodes and 345,546 variables.
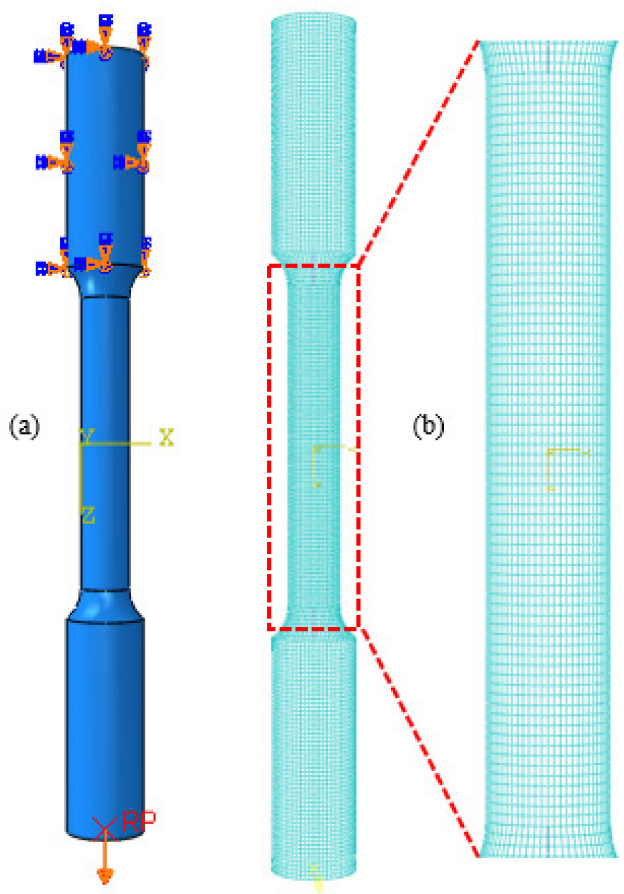

Figure 14. (a) Boundary conditions and (b) Meshed specimen with $1 \mathrm{~mm}$ node spacing.

The simulation results are imported to Fe-safe software [15] which is used to predict lives of specimens. Tension and compression steps of fully reversed loading, i.e., $\mathrm{R}=1$ are taken into consideration while calculating the fatigue life. The material properties used for life prediction are summarized in Table 4. The inputs required by the software are material properties and loading cycle. Stress-strain conversion takes place within Fe-safe by utilizing the elastic modulus of pore-free steel. The recommended algorithm by Fe-safe for predicting fatigue life of steel is Brown-Miller algorithm with Morrow mean stress correction [15]. 
Table 4. ASTM A216 WCB Steel Monotonic and Cyclic Properties [1,16].

\begin{tabular}{|c|c|c|}
\hline \multicolumn{3}{|c|}{ ASTM A216 WCB Monotonic Properties } \\
\hline Ultimate Tensile Strength, $\sigma_{\text {UTS }}$ & $(\mathrm{MPa})$ & 620 \\
\hline Yield Strength, $\sigma_{y}$ & $(\mathrm{MPa})$ & 355 \\
\hline Modulus of Elasticity, $E_{0}$ & $(\mathrm{MPa})$ & 198,000 \\
\hline Percentage Elongation, \%EL & - & 32.5 \\
\hline Fracture strength, $\sigma_{f}$ & $(\mathrm{MPa})$ & 293 \\
\hline \multicolumn{3}{|c|}{ ASTM A216 WCB Cyclic Properties } \\
\hline Fatigue Strength, $S_{f}$ & $(\mathrm{MPa})$ & 141 \\
\hline$S_{f} / \sigma_{\text {UTS }}$ & & 0.227 \\
\hline Cyclic Strain Hardening Coefficient, $K^{\prime}$ & $(\mathrm{MPa})$ & 1558 \\
\hline Cyclic Strain Hardening Exponent, $n^{\prime}$ & & 0.295 \\
\hline Fatigue Strength Coefficient, $\sigma_{f}^{\prime}$ & $(\mathrm{MPa})$ & 1015 \\
\hline Fatigue Strength Exponent, $b$ & & -0.136 \\
\hline Fatigue Ductility Coefficient, $\varepsilon_{f}^{\prime}$ & & 0.195 \\
\hline Fatigue Ductility Exponent, $c$ & & -0.435 \\
\hline
\end{tabular}

\subsection{Brown-Miller Analysis}

The Brown-Miller algorithm conservative approach for fatigue life prediction, using planes perpendicular to the surface and at 45 degrees to the surface. It uses a critical plane analysis to estimate the fatigue life in reversals to failure, $2 N_{f}$, by solving the following equation [15] at each node.

$$
\frac{\Delta \gamma_{\max }}{2}+\frac{\Delta \varepsilon_{\mathrm{n}}}{2}=1.65 \frac{\sigma_{\mathrm{f}}^{\prime}}{\mathrm{E}}\left(2 \mathrm{~N}_{\mathrm{f}}\right)^{\mathrm{b}}+1.75 \varepsilon_{\mathrm{f}}^{\prime}\left(2 \mathrm{~N}_{\mathrm{f}}\right)^{\mathrm{c}}
$$

With Morrow mean stress correction, Equation (1) is modified to

$$
\frac{\Delta \gamma_{\max }}{2}+\frac{\Delta \varepsilon_{\mathrm{n}}}{2}=1.65 \frac{\left(\sigma_{\mathrm{f}}^{\prime}-\sigma_{\mathrm{m}}\right)}{\mathrm{E}}\left(2 \mathrm{~N}_{\mathrm{f}}\right)^{\mathrm{b}}+1.75 \varepsilon_{\mathrm{f}}^{\prime}\left(2 \mathrm{~N}_{\mathrm{f}}\right)^{\mathrm{c}}
$$

where $\frac{\Delta \gamma_{\max }}{2}$ is the maximum shear strain amplitude, $\frac{\Delta \varepsilon_{\mathrm{n}}}{2}$ is the strain amplitude normal to the shear stress plane, $\sigma_{\mathrm{m}}$ is the mean stress, $\sigma_{\mathrm{f}}^{\prime}$ is the fatigue strength coefficient, $b$ is the fatigue strength exponent, $\varepsilon^{\prime}{ }_{\mathrm{f}}$ is the fatigue ductility coefficient, and $\mathrm{c}$ is the fatigue ductility exponent.

The critical plane analysis is used to compute the strain tensor at a FE node having three direct and three shear components. The strain tensor is then resolved onto a number of planes, where, at each place the damage associated with the strain is evaluated. The plane resulted with maximum damage is used in strain-life computations. For a Cartesian $x-y-z$ coordinate system, the unique planes can be defined by the orientation the normal of the plane surface makes with respect to the coordinate system [17]. This orientation can be defined by an angle from $x$-axis toward the $y$-axis, and another angle from the $z$-axis toward the $x-y$ plane [15]. Fe-safe searched for the critical plane having worst damage in 10-degree increments over the 180-degree range of the first angle and 90-degree range of the second angle. The strains are projected to the calculation plane using direction cosines.

\subsection{Results of Fatigue Life Simulations}

Figure 15 shows the simulated stress field in porous specimens, $\mathrm{S1}^{\prime}$ through $\mathrm{S} 7^{\prime}$, using ABAQUS and the fatigue life predicted by Fe-safe. The scale used for fatigue life is Log10 life, i.e., 1 million cycles are represented by 6 on this scale. As mentioned earlier, a node spacing of $1 \mathrm{~mm}$ is found to show good agreement between the measured and the predicted fatigue lives. A complex stress field is developed due to porosity upon loading each specimen. It is observed that area with stress concentrations experienced the shortest lives. Moreover, for each specimen, the least number of cycles to failure is predicted on the surface. This shortest life predicted is considered to be the fatigue life for that specimen. A 
summary of simulated stress, measured and predicted fatigue life for each specimens, is presented in Table 5.

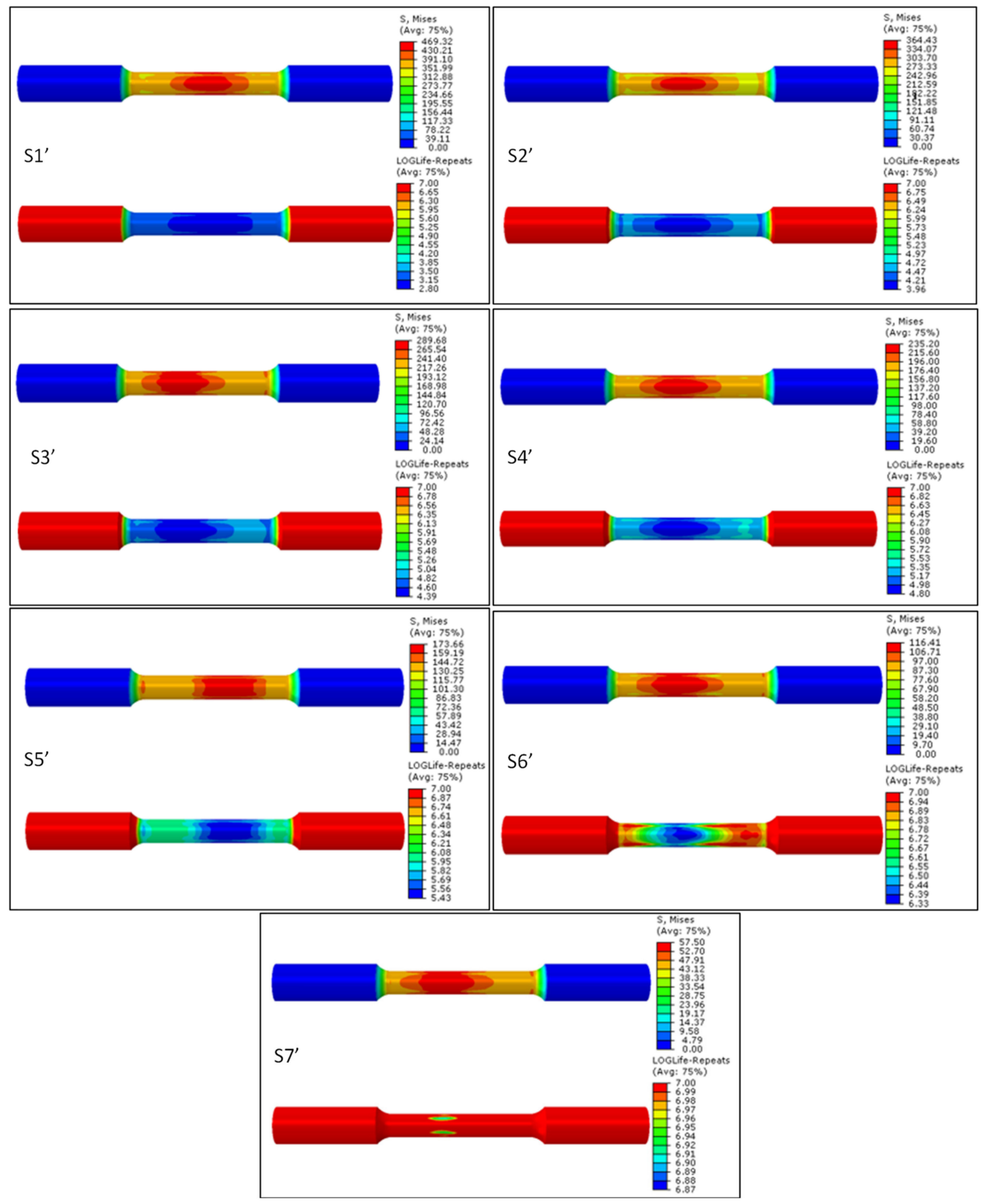

Figure 15. ABAQUS stress analysis and fatigue life prediction from Fe-safe. 
Table 5. Summary of simulated and experimental results of fatigue testing for steel specimens.

\begin{tabular}{cccc}
\hline Specimen ID & $\begin{array}{c}\text { Simulated Stress } \\
\text { (MPa) }\end{array}$ & $\begin{array}{c}\text { Measured Fatigue } \\
\text { Life (Cycles) }\end{array}$ & $\begin{array}{c}\text { Simulated Fatigue } \\
\text { Life (Cycle) }\end{array}$ \\
\hline S1' & 469.32 & 62 & 630 \\
S2 $^{\prime}$ & 364.43 & 6545 & 9115 \\
S3 $^{\prime}$ & 289.68 & 20,561 & 24,219 \\
S4 $^{\prime}$ & 235.20 & 56,893 & 62,983 \\
S5 $^{\prime}$ & 173.66 & 145,089 & 259,682 \\
S6 $^{\prime}$ & 116.41 & 535,564 & $2,133,921$ \\
S7 $^{\prime}$ & 57.50 & $3,061,195$ & $7,421,449$ \\
\hline
\end{tabular}

The experimental and simulated S-N curve are presented in Figure 16. Simulation results shows two specimens to experience the infinite life where the predicted number of cycles to failure are beyond the runout condition, i.e., $10^{6}$ cycles. For a better understanding of experimental and simulated results, the measured and simulated lives for all specimens are compared in Figure 17. A line of perfect correspondence is provided in the figure to determine if a prediction is non-conservative (above the line) or conservative (below the line). It can be observed that six out of seven specimens are within a factor of 10 of the test results, which can be considered as a good agreement in fatigue life prediction [18]. The specimen $\mathrm{S1}^{\prime}$ is found to have a relatively bad agreement since the predicted fatigue life is slightly more than the factor of 10 of the test result. In general, the overall results for fatigue life prediction are encouraging, however, the overall nature of predictions are found to be non-conservative in steel specimens.

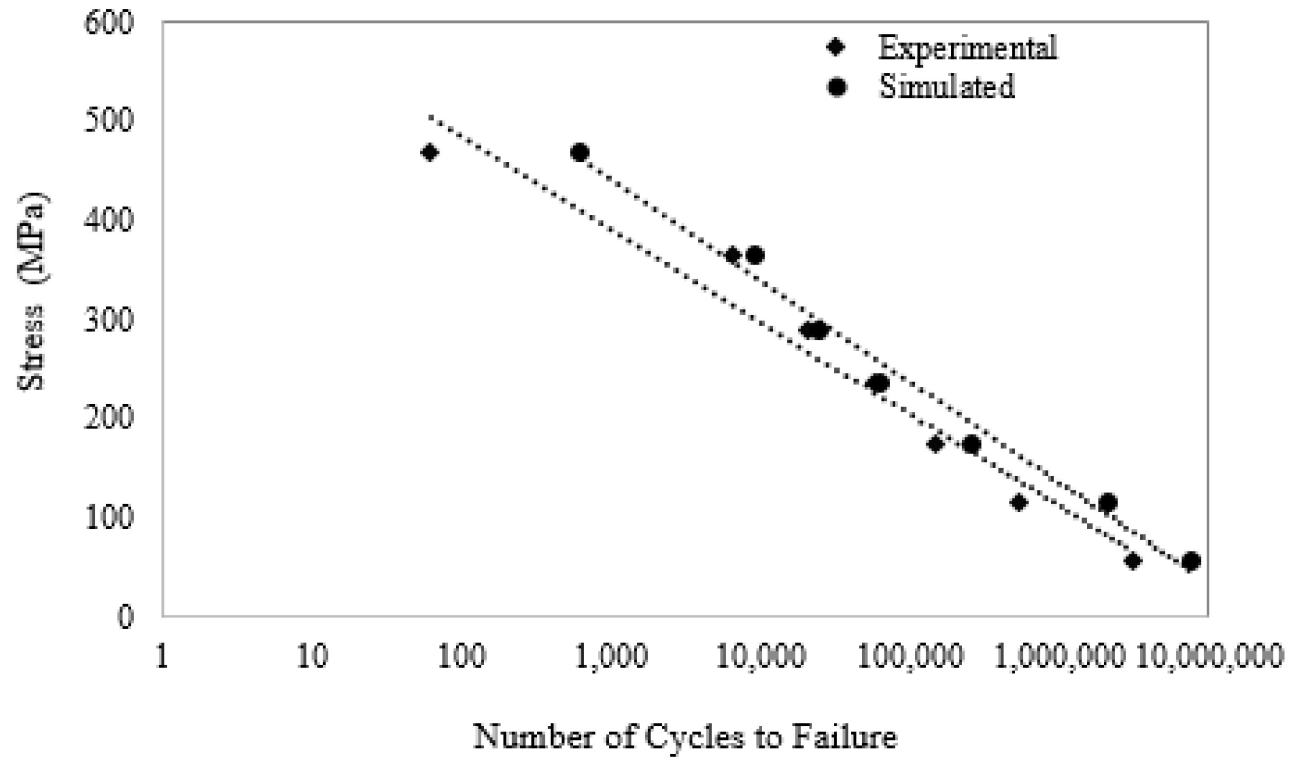

Figure 16. Simulated and experimental S-N curve for steel specimens. 


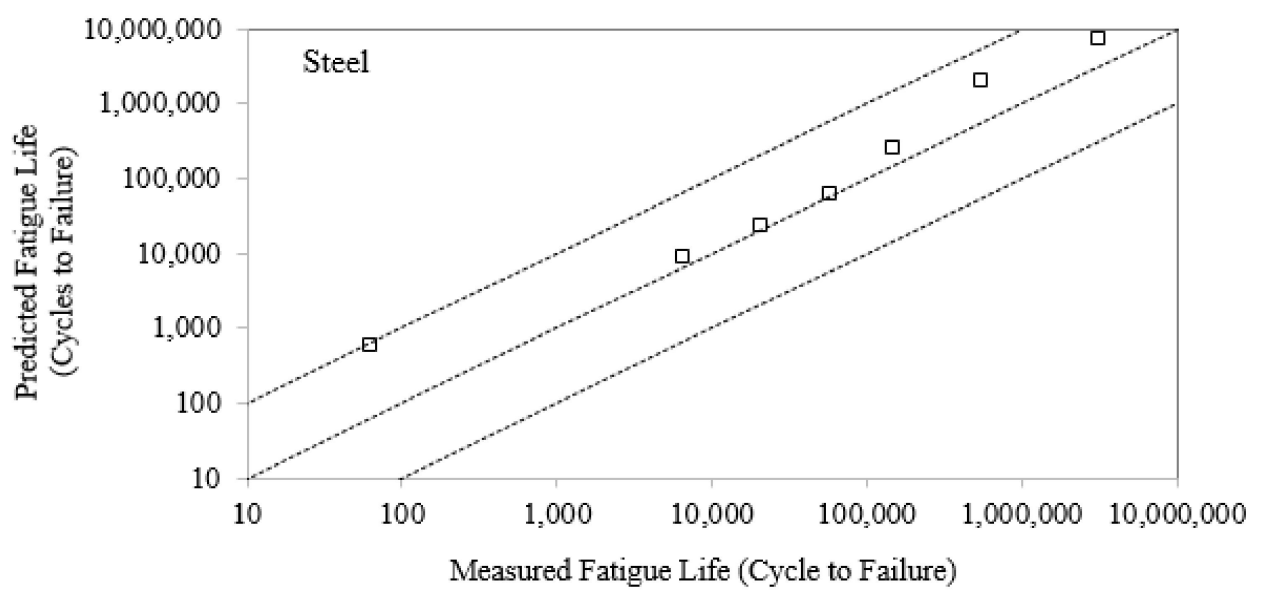

Figure 17. Measured and predicted fatigue lives of steel specimens.

\section{Reliability Analysis}

\subsection{Strength-Stress Model and Reliability Calculations}

The reliability of an engineering product deals with the undesirable events or failures during its service life. It can be precisely defined as the reliability of a part is the probability that, when operated under defined set of conditions, the part will perform its intended function adequately for a specified interval of time [19]. It is an established fact that apparently identical parts operating under similar conditions fail at different points in time. This brings about a need to describe failure phenomena in probabilistic terms and therefore, fundamental aspects of reliability heavily rely on concepts from probability.

The classic strength-limited design suggests the strength should be greater than the stress. A design factor is always added to cover the uncertainties. If strength and stress distributions are known, the reliability of a part can be determined using interference theory presented in [8]. For a strength-limited design, let the density function for the strength is $f_{1}$ and that for stress is $f_{2}$, the reliability function will be a joint probability function, where

$$
\begin{gathered}
P(S>\sigma)=P[S-\sigma>0]=R \\
R=\int_{-\infty}^{\infty} f_{1}(S)\left[\int_{S}^{\infty} f_{2}(\sigma) d \sigma\right] d S
\end{gathered}
$$

where, $\mathrm{S}$ is the significant strength and $\sigma$ is the significant load-induced stress. The task for a given design is to ensure that $S>\sigma$. Based on fatigue life of specimens obtained at different stress levels in Section 5, the reliability of cast specimens is estimated using this model in this work.

Reliability computations are done for two scenarios: (i) Time-independent loadinduced stress and (ii) Time-dependent load-induced stress. Four different load-induced stress values are selected based on the expected loading conditions on steel castings, i.e., $79 \mathrm{MPa}, 87 \mathrm{Mpa}, 96 \mathrm{Mpa}$ and $104 \mathrm{Mpa}$. FE-safe combines the variability in both material fatigue strength and applied loading (if any), to calculate the probability of failure for a specified life. For time-independent load-induced stress case, the reliability computations are based on normally distributed stress and Weibull distributed strength. The details of failure rate calculations are presented in [8].

The reliability analysis for time-dependent load-induced stress provides a more conservative estimate of component performance during service life. The strength-stress interference theory is also applicable for this scenario, but load-induced stress cannot be modeled through normal distribution. For this reason, Fe-safe could not be used for reliability computations in this case. Instead, analytical methods proposed by Samar et al. [20] 
are used, which models both the strength and the stress through Weibull distribution. The probability density function of strength $S$ and stress $\sigma$ distributions are given by:

$$
\begin{aligned}
& f_{1}(S)=\frac{\beta_{S}}{\theta_{S}}\left(\frac{S}{\theta_{S}}\right)^{\beta_{S}-1} \cdot \exp \left(-\frac{S}{\theta_{S}}\right)^{\beta_{S}} \\
& f_{2}(\sigma)=\frac{\beta_{\sigma}}{\theta_{\sigma}}\left(\frac{\sigma}{\theta_{\sigma}}\right)^{\beta_{\sigma}-1} \cdot \exp \left(-\frac{\sigma}{\theta_{\sigma}}\right)^{\beta_{\sigma}}
\end{aligned}
$$

And the resultant reliability function is similar to Equation (3). The change in loadinduced stress with time can be modeled through Rayleigh distribution, which is a special case of Weibull distribution with shape parameter $\beta$ equal to 2 . If $\beta_{S}=2 \beta_{\sigma}$, then the reliability analysis is based on Weibull distributed strength and Rayleigh distributed loadinduced stress [8]. Using the results presented by Samar et al. [20] and with $\beta_{S}=2 \beta_{\sigma}$, the reliability function is given by

$$
\mathrm{R}=\mathrm{P}(\mathrm{S}>\sigma)=\frac{\theta_{\mathrm{S}}}{\theta_{\sigma}} \sqrt{\pi} \cdot \exp \left(\frac{1}{4}\left(\frac{\theta_{\mathrm{S}}}{\theta_{\sigma}}\right)^{2}\right) \cdot\left\{1-\phi\left[\frac{1}{\sqrt{2}} \cdot\left(\frac{\theta_{\mathrm{S}}}{\theta_{\sigma}}\right)\right]\right\}
$$

Hence, the reliability can be estimated against the ratio of scale parameters, i.e., $\frac{\theta_{S}}{\theta_{\sigma}}$ for the targeted lives. Here, the $\frac{\theta_{S}}{\theta_{\sigma}}$ ratio is approximated to be similar to that of the $\frac{S}{\sigma}$ ratios for the targeted lives.

\subsection{Reliability Results}

Figures 18-21 depicts the reliability curves for steel specimens with load-induced stress values $79 \mathrm{MPa}, 87 \mathrm{MPa}, 96 \mathrm{MPa}$ and $104 \mathrm{MPa}$, respectively. In each of these figures, the reliability of the cast parts is presented with a $0 \%$ and $5 \%$ variability in the load-induced stress. It can be observed that a 5\% variability in load has not significantly affected the component's reliability. This could be due to the fact that the software derives an equivalent loading for non-constant amplitude loadings. However, the component reliability for the same targeted life decreases with increasing load induced stress. Moreover, the effect of Weibull shape parameter $\beta$ is also analyzed and presented. Previously, it is reported that the coefficient of variation in hardness and strength of the specimens is very less [1], which suggests a higher value of $\beta$ to be more realistic. Therefore, reliability is computed at various values of $\beta$, i.e., $3-5$ and 10 . The higher the value of $\beta$, the components will be more reliable for the same targeted lives as shown in Figures 18-21.

A summary of reliability computations for steel is presented in Figure 22. The plot indicates the reliability of components for the runout conditions used in fatigue life prediction, i.e., $10^{6}$ cycles against the load induced stress. A region of safe loading is defined based on how many components survive at a particular load. It is noted that, independent of $\beta$, more than $86 \%$ components survive for the infinite life at a load-induced stress of $85 \mathrm{MPa}$. However, this is a conservative estimate of safe loading on component to allow for possible variations in component strength, which is represented by $\beta$ in reliability calculations. From experience, it is readily accepted that apparently same components fail at different points of time during service life. Therefore, in a strength-limited design, it is appropriate to consider such variations in reliability computations. Nevertheless, if such variations are assured to be at a minimum, the use of a higher value of $\beta$ is more realistic, which in this case resulted in a reliability of more than $95 \%$ at a load induced stress of $95 \mathrm{MPa}$ in Figure 22. Hence, with the optimized mold design and a higher $\beta=10$, it is reasonable to infer a safe load-induced stress up to $95 \mathrm{Mpa}$. 

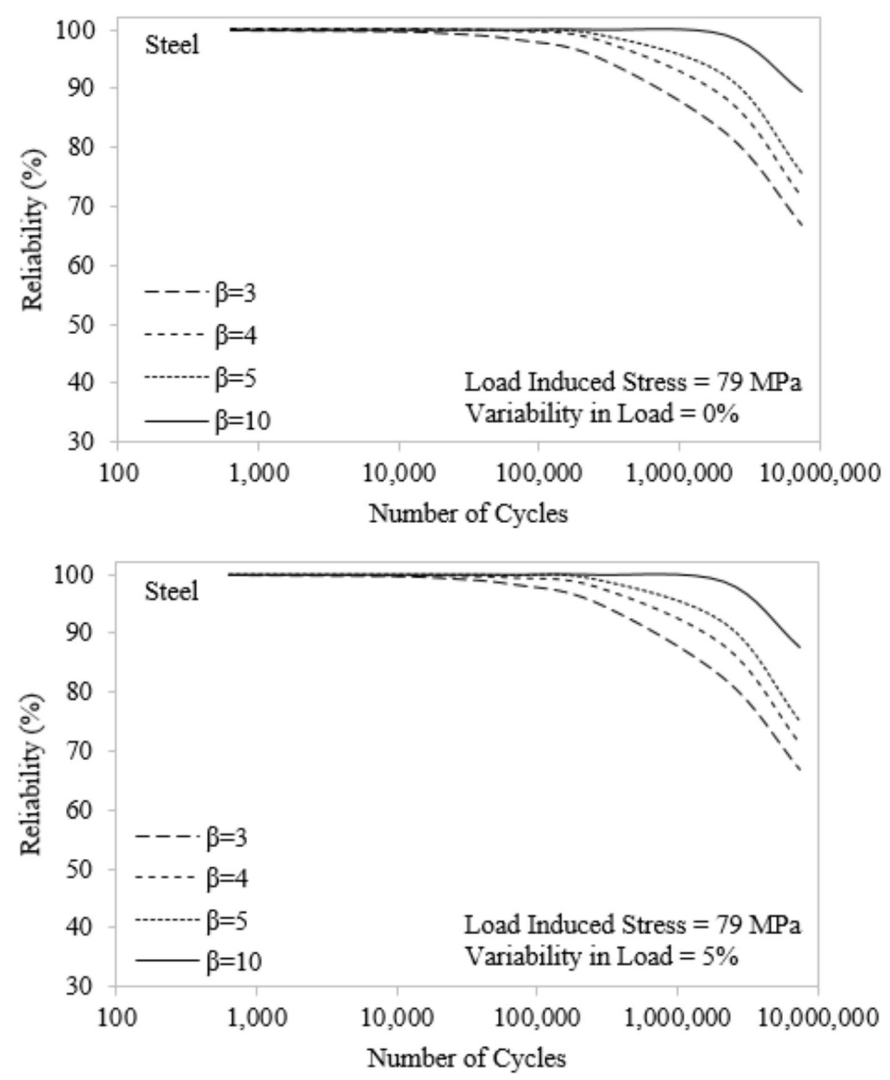

Figure 18. Reliability results with a load-induced stress of $79 \mathrm{MPa}$
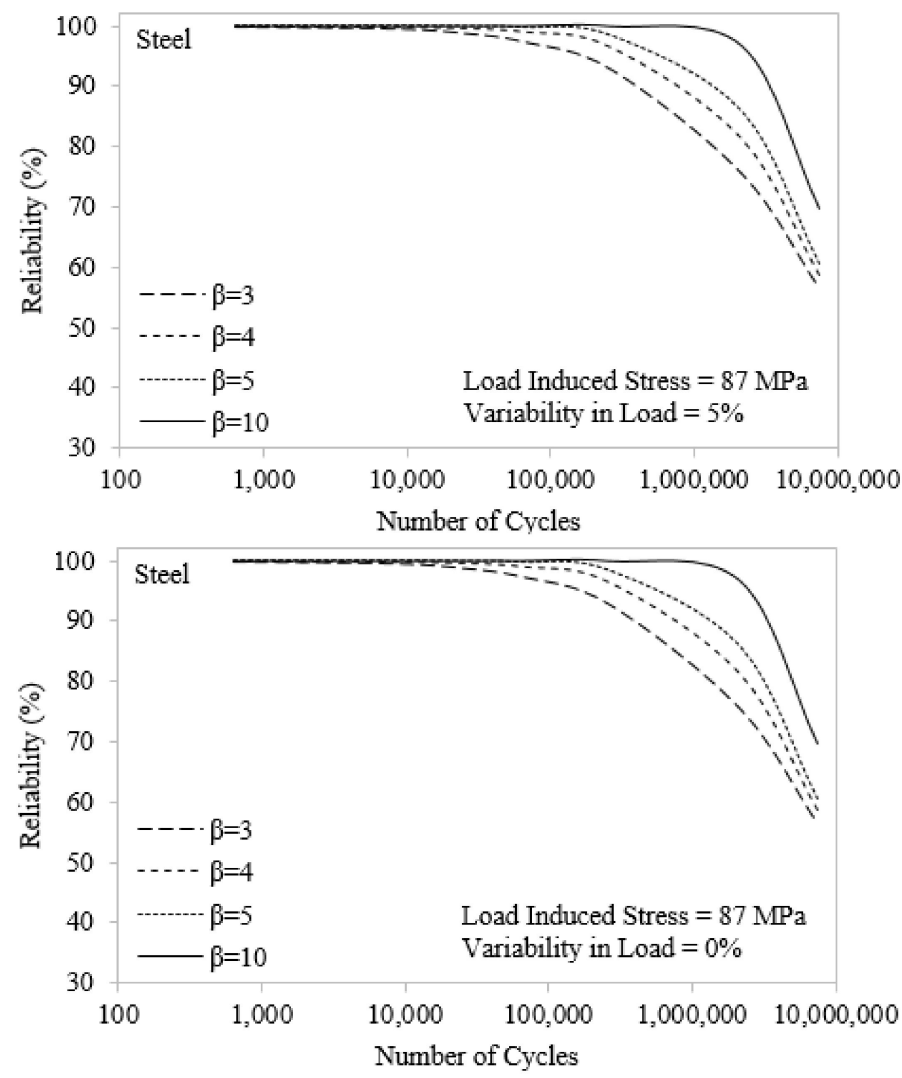

Figure 19. Reliability results with a load-induced stress of $87 \mathrm{MPa}$. 

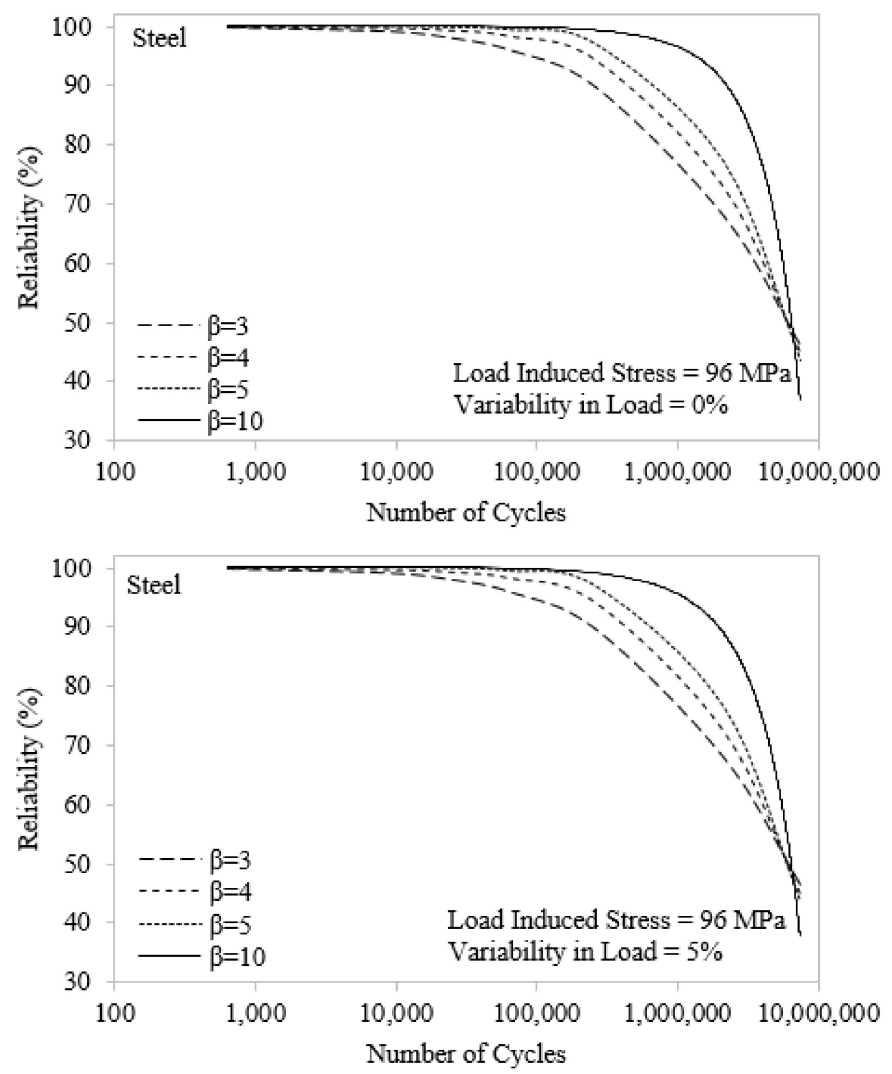

Figure 20. Reliability results with a load-induced stress of $96 \mathrm{MPa}$.
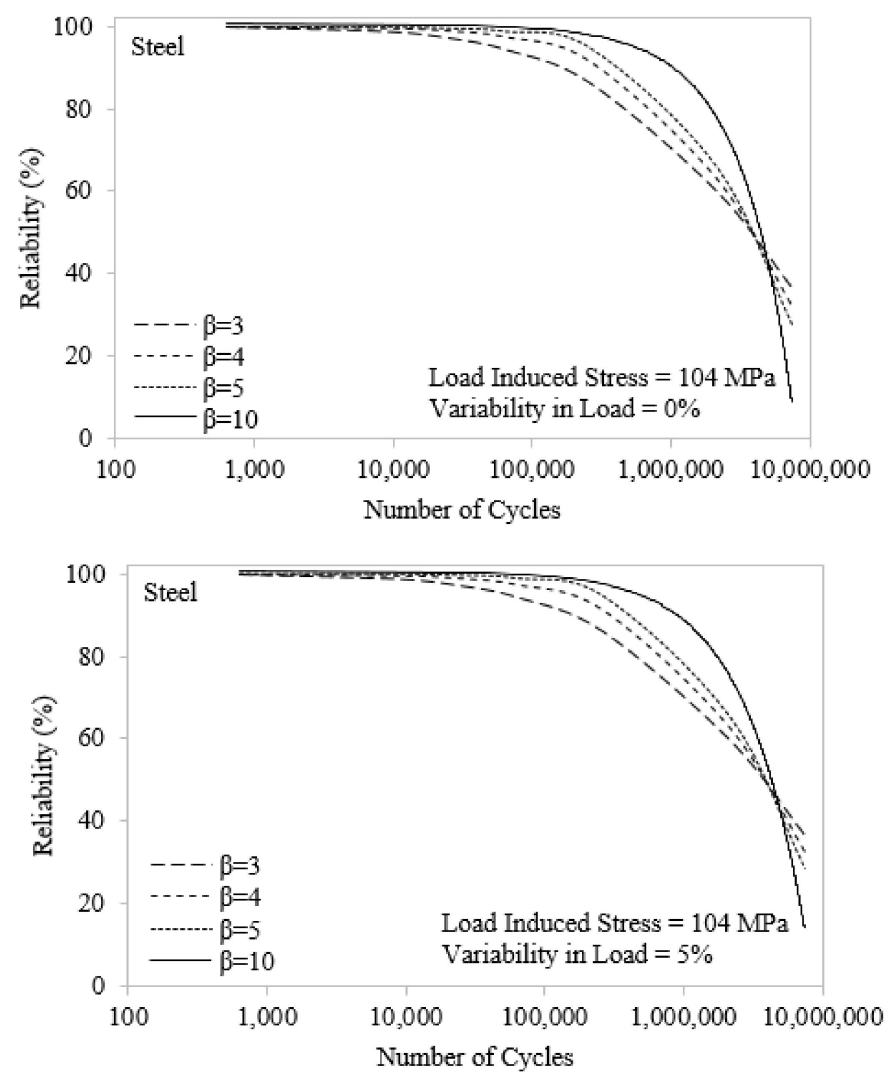

Figure 21. Reliability results with a load-induced stress of $104 \mathrm{MPa}$. 


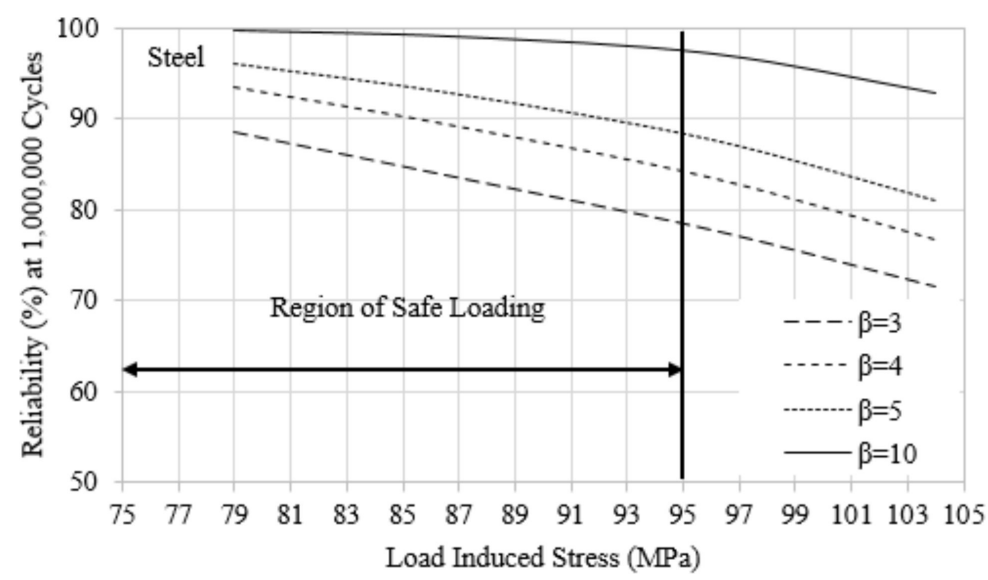

Figure 22. Summary of reliability results for cast steel.

Figure 23 shows the reliability results for time-dependent load induced stress based on Equation (6). Here, a plot of reliability of component versus the ratio of scale parameters, i.e., $\frac{\theta_{S}}{\theta_{\sigma}}$ in Weibull distribution is made to evaluate the results. It is evident from Figure 23 that the reliability of a component increases with increasing design factor. If the material's strength $S$ is four times the mean load-induced stress $\sigma$, the parts result in $\sim 90 \%$ reliability which reduces to $54.5 \%$ when $S=\sigma$. It should be noted that the results in Figure 23 are valid for $\beta_{S}=2 \beta_{\sigma}$ which suggests that the strength is Weibull distributed and load-induced stress is Rayleigh distributed.

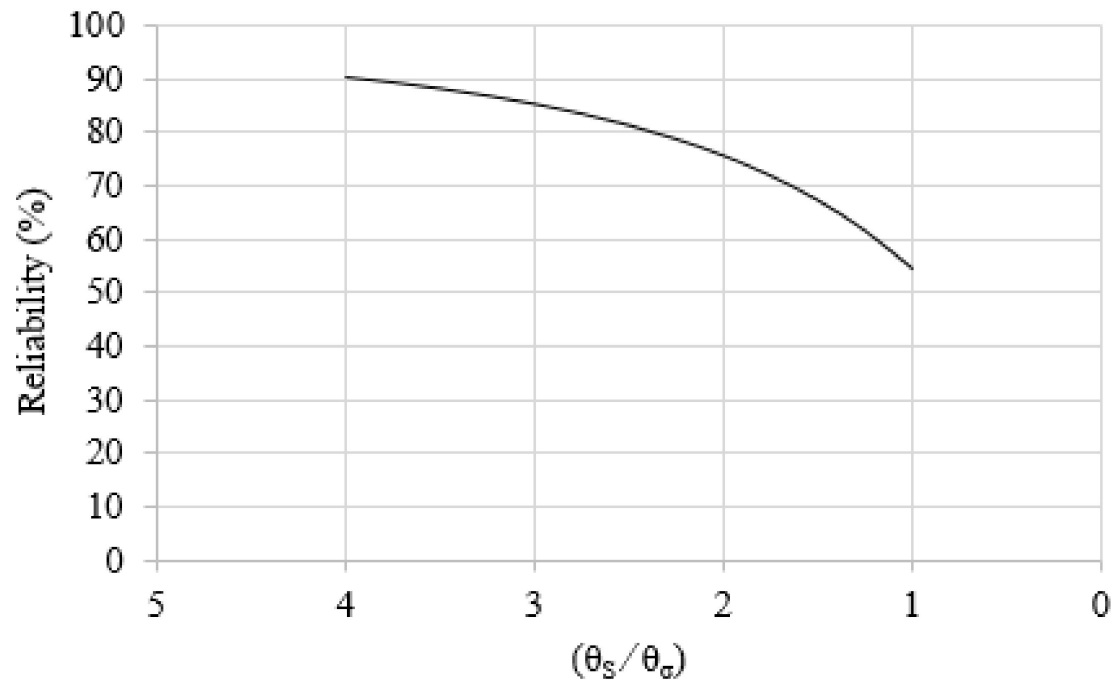

Figure 23. Reliability results for time-dependent load-induced stress.

\subsection{Distribution Fitting to Reliability Results}

The reliability results presented above can be used to determine reliability models by fitting probability distributions to these estimates. In this regard, log-normal distribution and Weibull distribution for the $79 \mathrm{MPa}$ stress with 5\% variability in load are used. The distribution fitting includes linearizing the reliability function, plotting of linearized reliability function, and finally estimating the distribution parameters. The log-normal distribution parameters are $\mu$ and $\sigma$, whereas, the Weibull distribution parameters are $\beta$ and $\theta$. For brevity, the procedure to obtain fitted models is introduced here briefly and the details are presented elsewhere [8]. The results for log-normal distribution and Weibull distribution fitted to reliability estimates are presented in Figures 24 and 25, respectively. 
The equations of fitted models are also included to determine the distribution parameters, which are summarized in Tables 6 and 7.

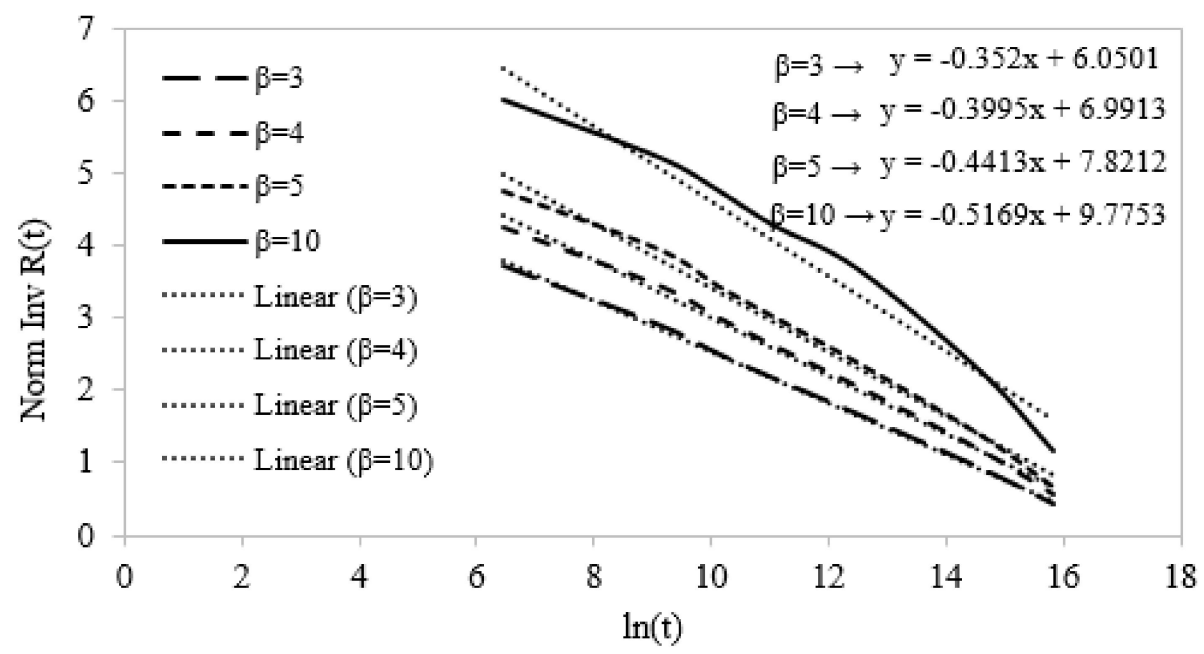

Figure 24. Log-Normal distribution fitted to reliability estimates with load-induced stress $79 \mathrm{MPa}$.

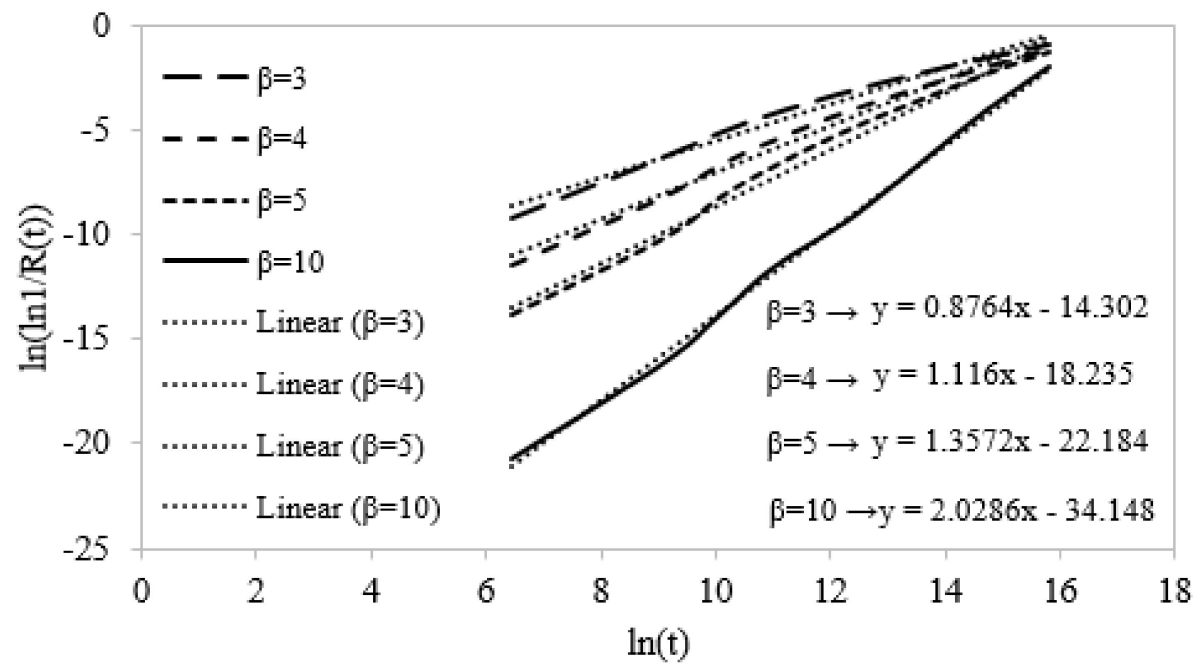

Figure 25. Weibull distribution fitted to reliability estimates with load-induced stress $79 \mathrm{MPa}$.

Table 6. Log-normal distribution parameters fitted to reliability estimates.

\begin{tabular}{ccc}
\hline \multirow{2}{*}{$\begin{array}{c}\text { Weibull Shape Parameter for } \\
\text { Reliability Estimate }\end{array}$} & \multicolumn{2}{c}{ Log-Normal Distribution Parameters } \\
\cline { 2 - 3 } & $\boldsymbol{\mu}$ & $\boldsymbol{\sigma}$ \\
\hline$\beta=3$ & 17.19 & 2.84 \\
$\beta=4$ & 17.50 & 2.50 \\
$\beta=5$ & 17.72 & 2.27 \\
$\beta=10$ & 18.91 & 1.93 \\
\hline
\end{tabular}


Table 7. Weibull distribution parameters fitted to reliability estimates.

\begin{tabular}{ccc}
\hline \multirow{2}{*}{$\begin{array}{c}\text { Weibull Shape Parameter for } \\
\text { Reliability Estimate }\end{array}$} & \multicolumn{2}{c}{ Weibull Distribution Parameters } \\
\cline { 2 - 3 } & $\boldsymbol{\beta}$ & $\boldsymbol{\theta}$ \\
\hline$\beta=3$ & 0.876 & $15,464,922$ \\
$\beta=4$ & 1.116 & $13,564,126$ \\
$\beta=5$ & 1.357 & $12,178,806$ \\
$\beta=10$ & 2.082 & $100,931,406$ \\
\hline
\end{tabular}

\section{Conclusions and Future Work}

This study presents a method for determining the fatigue life and reliability of ASTM A 216 WCB steel castings using advanced simulations tools. For simplicity, standard fatigue specimens are produced with an optimized and robust mold design. The life and reliability are predicted taking into consideration the porosities, which are minimized, yet exist to some extent in the specimens produced with optimized mold design. The key conclusions are as follows:

Casting simulation softwares such as MAGMASoft are capable of examining the effects of several factors such as temperature of molten metal, pouring time and velocity, gating and runner design, riser design, and mold configurations on the quality of castings.

- Testing of cast standard specimens is a practical approach to validate the quality of castings produced using simulation-based optimized mold designs.

0 The simulations done in this work utilizes the porosity fractions which are defined over a volume that is large compared to microscopic pore geometry. The good agreement between measured and simulated fatigue lives confirms the adequate mesh used in life prediction with integrated porosity. Nevertheless, it can be expected that stress concentration around very small shrinkage pores can be modeled better with further mesh refinement, which consequently will require longer simulation time and more powerful computational facilities.

- The classical strength-stress interference theory provides realistic estimates reliability. It is concluded that the reliability for infinite life drops down with increasing loadinduced stress. The overall results suggest $95 \mathrm{MPa}$ as a safe stress to survive the cast steel parts for an infinite life.

- The methodology presented in this work can be applied to real cast parts. Besides cast steels, the methodology is deemed robust in cradle to grave analysis of cast parts produced with almost any alloy.

Author Contributions: Conceptualization, M.A.A.K. and A.K.S.; methodology, M.A.A.K.; software, M.A.A.K.; validation, M.A.A.K., Z.M.G. and M.A.; formal analysis, M.A.A.K.; resources, Z.M.G.; data curation, M.A.A.K.; writing - original draft preparation, M.A.A.K. and A.K.S.; writing-review and editing, Z.M.G. and M.A.; supervision, A.K.S. All authors have read and agreed to the published version of the manuscript.

Funding: This research was funded by The National Science, Technology and Innovation Plan (NSTIP), Saudi Arabia, grant number 14-ADV890-04-R and the APC was funded by Prince Mohammad Bin Fahd University, Saudi Arabia.

Informed Consent Statement: Not Applicable.

Data Availability Statement: Not Applicable.

Acknowledgments: The simulations presented in this study are done at Rapid Prototyping and Reverse Engineering Lab at King Fahd University of Petroleum and Minerals (KFUPM). Special thanks to MAGMA and KFUPM for their continuous support during this work. The authors would also like to acknowledge the supportive environment provided by Prince Mohammad Bin Fahd University to facilitate the preparation of manuscript and its publication.

Conflicts of Interest: The authors declare no conflict of interest. 


\section{References}

1. Sheikh, A.K.; Khan, M.A.A. Mold Design Optimization and Quality Assessment of Steel Castings through Integrated Simulations and Experiments. J. Mech. Sci. Technol. 2020, 34, 2975-2983. [CrossRef]

2. Khan, M.A.A.; Sheikh, A.K. A Comparative Study of Simulation Software for Modelling Metal Casting Processes. Int. J. Simul. Model. 2018, 17, 197-209. [CrossRef]

3. Futáš, P.; Pribulová, A.; Fedorko, G.; Molnár, V.; Junáková, A.; Laskovský, V. Failure Analysis of a Railway Brake Disc with the Use of Casting Process Simulation. Eng. Fail. Anal. 2019, 95, 226-238. [CrossRef]

4. Demler, E.; Götze, S.; Herbst, S.; Nürnberger, F.; Maier, H.J.; Ursinus, J.; Büdenbender, C.; Behrens, B.-A. Casting Manufacturing of Cylindrical Preforms Made of Low Alloy Steels. Procedia Manuf. 2020, 47, 445-449. [CrossRef]

5. Lei, C.; Yang, Y.; Yang, G.; Huang, Y. Magma Software Simulation Assisted Optimization of the Casting System of Turbocharger Castings. Procedia Manuf. 2019, 37, 59-65. [CrossRef]

6. Sunanda, A.; Jagannadha Raju, M.V. Simulation for Prediction Analysis of Defects in Pulley Casted Using Sand Casting Process. Mater. Today Proc. 2021; in press. [CrossRef]

7. Kumar, R.; Madhu, S.; Aravindh, K.; Jayakumar, V.; Bharathiraja, G.; Muniappan, A. Casting Design and Simulation of Gating System in Rotary Adaptor Using Procast Software for Defect Minimization. Mater. Today Proc. 2020, 22, 799-805. [CrossRef]

8. Sheikh, A.K.; Khan, M.A.A. Fatigue Life Prediction and Reliability Assessment of Ductile Iron Castings Using Optimized Mold Design. Int. J. Adv. Manuf. Technol. 2020, 106, 1945-1966. [CrossRef]

9. Schmiedel, A.; Kirste, T.; Morgenstern, R.; Weidner, A.; Biermann, H. The Fatigue Life of 42CrMo4 Steel in the Range of HCF to VHCF at Elevated Temperatures up to 773 K. Int. J. Fatigue 2021, 152, 106437. [CrossRef]

10. Foglio, E.; Gelfi, M.; Pola, A.; Goffelli, S.; Lusuardi, D. Fatigue Characterization and Optimization of the Production Process of Heavy Section Ductile Iron Castings. Int. J. Met. 2017, 11, 33-43. [CrossRef]

11. Borsato, T.; Ferro, P.; Berto, F.; Carollo, C. Mechanical and Fatigue Properties of Pearlitic Ductile Iron Castings Characterized by Long Solidification Times. Eng. Fail. Anal. 2017, 79, 902-912. [CrossRef]

12. Hattel, J. Fundamentals of Numerical Modelling of Casting Processes; Polyteknisk Forlag: Kongens Lyngby, Denmark, 2005; ISBN 978-87-502-0969-0. Available online: https://orbit.dtu.dk/en/publications/fundamentals-of-numerical-modelling-ofcasting-processes (accessed on 12 November 2021).

13. Egner-Walter, A.; Kothen, M. Using Stress Simulation to Tackle Distortion and Cracking in Castings. Metall. Sci. Tecnol. 2013, 24. Available online: http:/ /78.47.113.247/index.php/MST/article/view/1122 (accessed on 12 November 2021).

14. ASTM E466-15 Standard Practice for Conducting Force Controlled Constant Amplitude Axial Fatigue Tests of Metallic Materials. 2015. Available online: https:/ / ci.nii.ac.jp/naid/10017283294/ (accessed on 12 November 2021).

15. Dassault Systems UK Limited Fe-Safe User Manual, 2015.

16. Khan, M.A.A. Development of a Simulation-Based Methodology for Mold Design Optimization and Reliability Assessment of Cast Parts-KFUPM EPrints; King Fahd University of Petroleum and Minerals: Dhahran, Saudi Arabia, 2018.

17. Hardin, R.A.; Beckermann, C. Prediction of the Fatigue Life of Cast Steel Containing Shrinkage Porosity. Metall. Mater. Trans. A 2009, 40, 581-597. [CrossRef]

18. Hardin, R.A.; Beckermann, C. Integrated Design of Castings: Effect of Porosity on Mechanical Performance. IOP Conf. Ser. Mater. Sci. Eng. 2012, 33, 012069. [CrossRef]

19. Kapur, K.C.; Lamberson, L.R. Reliability in Engineering Design; Wiley: Hoboken, NJ, USA, 1977; ISBN 978-0-471-51191-5. Available online: https:/ / ui.adsabs.harvard.edu/abs/1977nyjw.book.....K/abstract (accessed on 12 November 2021).

20. Samar Ali, S.; Kannan, S. A Diagnostic Approach to Weibull-Weibull Stress-strength Model and Its Generalization. Int. J. Qual. Reliab. Manag. 2011, 28, 451-463. [CrossRef] 